\title{
Characterization and Evaluation of a Novel Conserved Membrane Antigen P35 of Mycoplasma synoviae
}

\author{
Qianjin Sun ${ }^{1 \dagger}$, Xiaona Wei ${ }^{2,3,4 t}$, Wei Chen ${ }^{1}$, Qian Zhong ${ }^{1}$, Zhuanqiang Yan ${ }^{3,4}$, \\ Qingfeng Zhou ${ }^{3,4}$, Yongchang $\mathrm{CaO}^{2}$ and Feng Chen ${ }^{1 *}$ \\ ${ }^{1}$ College of Animal Science, South China Agricultural University, Guangzhou, China, ${ }^{2}$ State Key Laboratory of Biocontrol, \\ School of Life Sciences, Sun Yat-sen University, Guangzhou, China, ${ }^{3}$ Guangdong Enterprise Key Laboratory for Animal \\ Health and Environmental Control, Wen's Foodstuff Group Co., Ltd., Yunfu, China, ${ }^{4}$ Wen's Group Academy, Wen's \\ Foodstuffs Group Co., Ltd., Xinxing, China
}

OPEN ACCESS

Edited by:

Jianzhu Liu,

Shandong Agricultural University, China

Reviewed by:

Muhammad Akbar Shahid, Bahauddin Zakariya

University, Pakistan

Alvaro Menin

Federal University of Santa

Catarina, Brazil

Khalid Mehmood,

Islamia University of

Bahawalpur, Pakistan

*Correspondence: Feng Chen

fengch@scau.edu.cn

tThese authors have contributed equally to this work and share first authorship

Specialty section:

This article was submitted to Comparative and Clinical Medicine,

a section of the journal

Frontiers in Veterinary Science

Received: 15 December 2021

Accepted: 10 January 2022

Published: 23 February 2022

Citation:

Sun Q, Wei X, Chen W, Zhong Q,

Yan Z, Zhou Q, Cao Y and Chen F (2022) Characterization and Evaluation

of a Novel Conserved Membrane Antigen P35 of Mycoplasma synoviae.

Front. Vet. Sci. 9:836110

doi: 10.3389/fvets.2022.836110
Mycoplasma synoviae (MS) is a major avian pathogen that causes respiratory damage, infectious synovitis, and arthritis in chickens and causes serious economic losses to the global poultry industry. Despite its significance, knowledge on pathogenicity and pathogenic mechanism of MS is lacking, especially regarding its antigens. Bioinformatic analysis showed that the known MS proteins are only the tip of the iceberg among many MS membrane proteins. In this study, we identified and expressed a novel MS membrane protein P35. Sequence similarity showed that P35 was conservative and commonly existed among MS strains. Membrane protein extraction and immunofluorescence assay confirmed that P35 was distributed on the surface of MS. The production of specific antibodies after immunization with recombinant protein rP35 suggested its immunogenicity. The antigenicity of P35 was evaluated from two aspects by using polyantiserum against MS and rP35. Furthermore, in assays to identify the immune peptides of P35, all successfully expressed truncated segments could react with positive polyantiserum of MS, suggesting that P35 had more than one immune peptide. In conclusion, our study successfully identified P35 as a conservative antigen of MS, which may act as a potential candidate for the future development of a vaccine against MS.

Keywords: Mycoplasma synoviae, membrane protein, novel antigen, immunogenicity, antigenicity

\section{INTRODUCTION}

Mycoplasma synoviae (MS) is an important pathogen in the poultry industry. MS infection can cause subclinical to acute and chronic respiratory damage, infectious synovitis, and arthritis in chickens (1-3). Although, MS infections rarely cause direct death of chickens, they lead to obvious lameness, growth retardation, lower availability of ketone bodies, lower egg production rate, and higher eggshell apex abnormalities, leading to serious economic losses in the poultry industry (4-6). Besides, MS co-infections with other infectious agents such as Newcastle disease virus, Escherichia coli, and Mycoplasma gallisepticum increase economic losses (7-10).

With the emergence of drug-resistant strains (11-13), vaccination is the most effective way to control MS, combined with hygiene and management procedures $(14,15)$. However, current vaccines are not able to prevent transmission of MS $(16,17)$ and are expensive, as in vitro growth requires a rich medium and is time-consuming $(18,19)$. The development of more effective 
and cheaper vaccines requires to identify and characterize antigens of MS. Also, investigation on pathogenicity mechanism and serological detection methods are hampered by the lack of known and well-characterized MS antigens. However, only a few antigens have been identified so far, such as lipoprotein MSPB, elongation factor $\mathrm{EF}-\mathrm{Tu}$, enolase, NADH oxidase, hemagglutinin MSPA, ATP synthase beta chain, trigger factor, pyruvate kinase, chaperone DnaK, and pyruvate dehydrogenase complex E1 alpha and beta subunits $(20,21)$. But the immunogenicity and antigenicity of these proteins have not been thoroughly studied. Our analysis of the MS genome showed that there were still a large number of hypothetical antigens that had not been identified, and more research is needed on MS immunogenic proteins.

Mycoplasma lack cell walls, and since the cytoplasmic membrane components are directly in contact with host cells, they are generally thought to play an important role in survival, replication, and virulence compared to those in other bacterial species with cell walls (22); however, many mycoplasma proteins remain hypothetical (23). Many mycoplasma gene products have little or no detectable sequence similarity to those characterized in other bacteria (24). Improved understanding of the molecular pathogenesis of mycoplasmas will thus depend on the characterization of the function of these proteins that appear to be specific to the mycoplasmas $(25,26)$. Experimental validation of the functions of surface proteins of mycoplasma has been identified as one of the critical gaps in understanding this pathogen (27).

\section{MATERIALS AND METHODS}

\section{In silico Analysis of Mycoplasma synoviae Genome}

Bioinformatic analysis of MS genome (WVU1853, NZ_CP011096.1) was carried out with several online resources. Without the cell wall, membrane proteins of MS were the focus of analysis. Psortb v3.0 was used to detect cellular location (cytoplasmic, cytoplasmic membrane, outer membrane, or extracellular) (28). BOMP was used to detect integral $\beta$-barrel outer membrane proteins (29). Lipoprotein and signal peptides were analyzed by LipoP 1.0 (http://www.cbs.dtu.dk/services/ LipoP/). HMMER 3.2.1 software and Pfam v32.0 database were used to identify the functional domain of proteins (30). Lipoproteins with strong $\beta$-barrel signaling on the cell membrane were identified as potential immunogenic proteins. Then these proteins were subjected to functional domain identification and functional classification. A total of 149 membrane-associated proteins were preliminarily identified. Based on proteins scores in each prediction, we selected 27 proteins for further study. Of these 27 proteins, eight were hypothetical proteins, and P35 was one of them.

For the bioinformatic analysis of hypothetical protein P35, amino acid sequence similarity was compared by Basic Local Alignment Search Tool (BLAST) analysis at the National Center for Biotechnology Information (NCBI; http://www.ncbi. nlm.nih.gov). Physical data such as theoretical pI, molecular weight, and extinction coefficients were collected using the ProtParam tool at ExPASy (https://www.expasy.org/) (31). Theoretical transmembrane domain and signal peptide scores were identified using the TMHMM (http://www.cbs.dtu.dk/ services/TMHMM/) and SignalP (http://www.cbs.dtu.dk/ services/SignalP/) web services, respectively. B-cell epitopes of P35 were predicted using Immune Epitope Database (IEDB) (http://tools.iedb.org/main/). As TGA codons act as terminators in E. coli and as tryptophan codons in mycoplasmas, proteins with more than five TGA-coded tryptophans were excluded.

\section{Gene Homology Analysis}

Due to the lack of gene sequences of $p 35$ in the NCBI database, we designed and synthesized specific primers to amplify and sequence $p 35$ genes from MS isolated strains. The homology of $p 35$ genes was calculated using MegAline with the ClustalW method.

\section{Cloning, Expression, and Purification of Recombinant Protein}

To obtain the P35, the pSYNO-1 expression vector with chloramphenicol resistance site containing the target CDS was synthesized by Convenience Biology (Changzhou, China). The TGA codon contained in CDS was changed to TGG in the DNA sequence sent for synthesis. E. coli pGro7/BL21(DE3) cell (BJBALB, Beijing, China) was used for protein expression. For the solubility test, $50 \mathrm{ml}$ of LB containing $100 \mathrm{mg} / \mathrm{ml}$ of kanamycin and $25 \mu \mathrm{g} / \mathrm{ml}$ of chloramphenicol was inoculated with $500 \mu \mathrm{l}$ of pGro7/BL21(DE3) and incubated at $37^{\circ} \mathrm{C}$ with shaking to the optical density $600(\mathrm{OD} 600)>0.600$. Then, $50 \mu \mathrm{g} / \mathrm{ml}$ of IPTG was added to the broth culture. Induction expression was carried out at $25^{\circ} \mathrm{C}$ overnight. The culture was centrifuged, and the pellet was homogenized with $0.1 \mathrm{M}$ of Tris-HCl. Cells were lysed by sonication for $2 \mathrm{~min}, 4 \mathrm{~s}$ on and $4 \mathrm{~s}$ off pulse, $30 \%$ of amplitude (JY92-IIDN, SCIENTZ, Ningbo, China). Final samples were centrifuged, and the pellets homogenized in a suitable buffer. The presence of the MBP-tagged proteins in all fractions was determined using sodium dodecyl sulfate-polyacrylamide gel electrophoresis (SDS-PAGE) followed by Western blotting using anti-MBP (maltose-binding protein) antibody.

For protein purification, the supernatant of lysed samples was collected and purified in a nickel chelating resin (High Affinity Ni-Charged Resin FF Prepacked Column, GenScript, Nanjing, China) under suitable conditions. Chromatographic fractions were collected using an imidazole gradient and visualized in SDS-PAGE. Protein concentrations were determined using NanoPhotometer ${ }^{\circledR}$ NP80 (IMPLEN, Westlake Village, CA, USA).

\section{Production of Polyclonal Antibodies of Recombinant Protein}

The purified protein $\mathrm{rP} 35$ or MBP was diluted in oil adjuvant (Beyotime, Shanghai, China) at a ratio of 2:3 according to the manufacturer's instructions. Twelve 10-day-old specific pathogen-free (SPF) chickens were used to raise serum against rP35 and MBP. Two doses of purified protein were administered by subcutaneous injection at a 14-day interval. Blood samples 
were collected from the wing vein at $0,7,14,21$, and 28 days after the first inoculation (DAI), and isolated serums were stored at $-80^{\circ} \mathrm{C}$ before being processed. All animal experiments were supervised by the Institutional Animal Care and Use Committee of Sun Yat-sen University (SYSU-IACUC2021-B0507) and used in accordance with the regulation and guidelines of this committee.

\section{Antigenicity Assays of Chimeric Protein}

To identify whether P35 has antigenicity, ELISA and Western blotting assay were performed. For ELISA, microtiter plates were coated with $40 \mu \mathrm{g} /$ well of purified protein or $10^{8} \mathrm{CCU} /$ well of MS isolated strain named SD2. Serum samples of purified protein and MS SD2 strain originating from SPF chickens were used as primary antibodies with dilution at a ratio of $1: 1,000$. The negative serum samples were obtained from animals without vaccine or infection. Horseradish peroxidase (HRP)-conjugated goat anti-chicken IgG (KPL, USA) was used as a secondary antibody with 1:5,000 dilution. For Western blotting assay, the same antibodies were used as those in ELISA.

\section{Immunofluorescence Assays}

The localization of P35 on the MS surface was determined using immunofluorescence assays. MS SD2 cells were collected at the mid-logarithmic phase by centrifuging at 5,000 $\times \mathrm{g}$ for $5 \mathrm{~min}$ and washed three times with phosphate-buffered saline (PBS). The cell pellets were resuspended in PBS containing 5\% (w/v) skim milk and incubated for $1 \mathrm{~h}$ at $37^{\circ} \mathrm{C}$. After centrifugation and washing, cells were resuspended in polyantiserum of rP35 (1:500) or MBP (1:500) and incubated for $1 \mathrm{~h}$ at $37^{\circ} \mathrm{C}$. Cells were washed three times and incubated with fluorescein isothiocyanate (FITC)-conjugated goat anti-chicken IgG $(1: 1,000, \mathrm{KPL})$ at $4^{\circ} \mathrm{C}$ for $1 \mathrm{~h}$. The cells were washed three times, spread onto glass slides, and observed by fluorescence microscope (TCS SP8, Leica, Wetzlar, Germany).

\section{Extraction of Membrane Protein}

MS membrane proteins were extracted using Bacterial Membrane Protein Extraction Kit (KALANg, Shanghai, China) according to the manufacturer's instruction. Briefly, MS SD2 cells were collected at the mid-logarithmic phase by centrifuging at 5,000 $\times \mathrm{g}$ for $5 \mathrm{~min}$ and washed twice with PBS. Then $500 \mu \mathrm{l}$ of extracting solution A was added to cells and vortexed fully at $4^{\circ} \mathrm{C}$ for $1 \mathrm{~h}$ until cells were completely lysed. The lysate was centrifuged at $4^{\circ} \mathrm{C} 12,000 \times \mathrm{g}$ for $5 \mathrm{~min}$. The supernatant was collected and incubated at $37^{\circ} \mathrm{C}$ for $10 \mathrm{~min}$ and then centrifuged at $1,000 \times \mathrm{g}$ for $3 \mathrm{~min}$. The top solution was a mixture of cytoplasmic proteins, and the bottom solution was a mixture of membrane proteins. The membrane proteins were dissolved with $100 \mu \mathrm{l}$ of cold solvation reagent. The samples of cytoplasmic proteins and membrane proteins were stored at $-80^{\circ} \mathrm{C}$ for later use.

\section{Immune Epitope Region of P35}

To identify which region of P35 has antigenicity, we divided the protein into five segments for truncated expression, named SP1, SP2, SP3, SP4, and SP5. The expression vector and purification process were the same as those of rP35. SDS-PAGE and Western blotting assays verified the expression of truncated proteins. ELISA and Western blotting assay with the polyantiserum of MS as the primary antibody were carried out to confirm the antigenicity.

\section{Statistical Analysis}

Statistical analysis was performed using GraphPad Prism 8.0. The data were initially analyzed by the Kolmogorov-Smirnov test to verify the distribution of the data. To evaluate the reactivity between the recombinant proteins with the chicken antiserum in ELISA, two way-ANOVA was performed when comparing more than two groups. Data were expressed as mean \pm SD. Statistical differences were considered significant when $p<0.05$ using a 95\% CI.

\section{RESULTS}

\section{Bioinformatic Selection and Evaluation of Antigenic Proteins}

The genome of the MS WVU1853 strain, obtained from the NCBI database, contains 675 protein coding sequences (CDSs). Among these CDSs, Psortb predicted 149 CDSs to be located on the cytoplasmic membrane, 14 CDSs were extracellular, and 227 CDSs were unknown. After analysis with BOMP, LipoP 1.0, and Pfam, we identified that P35 was located on the cell membrane, was not a lipoprotein, and had signal peptide and was therefore selected for further analysis in this study.

Homology detections with BLAST tools showed that P35 had a low similarity with other type mycoplasma proteins; the highest identity among the results was $31.03 \%$ with hypothetical protein of Mycoplasma columborale (Figure 1A). After ProtParam analysis, the theoretical molecular weight of P35 was $45.788 \mathrm{kDa}$, and the theoretical pI was 5.71 . The TMHMM and SignalP algorithms identified a transmembrane domain from residues 10 to 32 (probability $>0.98$ ) and a signal peptide (likelihood was 0.8983).

\section{Generality and Conservatism Analysis of p35 Gene}

To prove that P35 is a universal protein of MS, the specific amplification primers of $p 35$ genes were designed and synthesized, and 18 p35 genes from different MS isolates were amplified and sequenced. A total of 6 p35 genes (from strains of 53, NCTC10124, WVU1853, 86079-7NS, HN01, and MS-H) were downloaded from the NCBI database. A total of 24 sequences were used for the homology analysis of $p 35$ gene. As shown in Figure 1B, the identity of $p 35$ genes was among $99.3 \%$ to $100 \%$. These results showed that $P 35$ is a common and conservative protein on MS.

\section{Recombinant Protein Expression and Purification}

The pSYNO-1 expression vector we used in this study contains the MBP tag, which will increase the molecular weight of the target protein by about $40 \mathrm{kDa}$. As shown in Figure $2 \mathbf{A}$, the recombinant protein ( $\mathrm{rP} 35)$ was soluble, and the molecular 


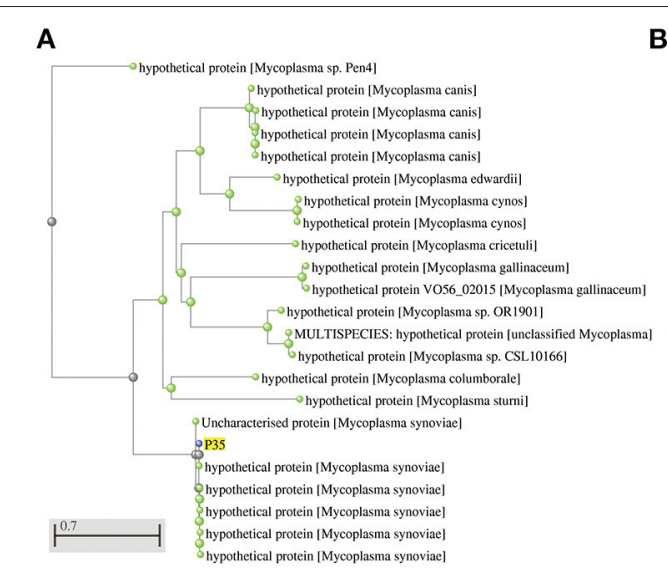

B

FIGURE 1 | Homology analysis of P35. (A) Molecular evolutionary tree analysis of P35. This tree was drawn on National Center for Biotechnology Information (NCBI) after being blasted with amino acid sequences of P35. The green points mean the blasted results of P35, and the blue point is P35. (B) Sequence distance of p35 gene among different Mycoplasma synoviae (MS) strains. A total of 24 sequences were used to calculate the homology by MegAline, among which 18 sequences were amplified and sequenced from MS isolates, and 6 sequences (53, NCTC10124, WVU1853, 86079-7NS, HNO1, and MS-H) were obtained from NCBI database. ${ }^{\star \star \star *}$ The consistency of the same strain, which means $100 \%$ similarity.
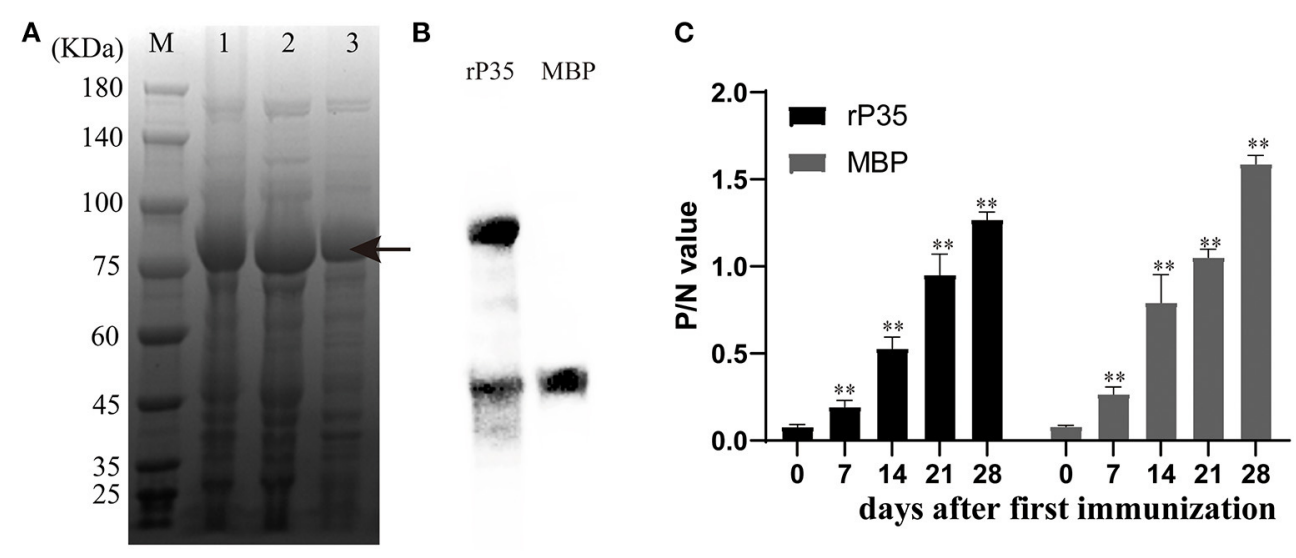

FIGURE 2 | Expression and preparation of polyantiserum of rP35. (A) Coomassie Blue staining of the Mycoplasma synoviae (MS) protein expressed in Escherichia coli BL21 (DE3) and run on 10\% polyacrylamide gels. Lane M: standard protein marker. Lane 1: total cell extract of E. coli BL21 (DE3). Lane 2: soluble fraction of the total bacterial extract after induction. Lane 3: protein purified by nickel column. The two bands in lane 3 may be the fractured recombinant proteins during purification. (B) Western blotting assay to verify the successful expression of recombinant protein. The right lane is MBP protein and the left lane is recombinant protein rP35. The primary antibody used was monoclonal antibody of anti-MBP tag. (C) Production of polyantiserum of rP35. rP35- and MBP-specific lgG responses induced in specific pathogen-free (SPF) chickens immunized with protein $(400 \mu \mathrm{g})$ performed using blood samples collected every 7 days for 28 days. ${ }^{* *}$ means there were significant differences; Arrow means the target protein we obtained.

weight was $\sim 87 \mathrm{kDa}$. The purified recombinant protein presented a single band. Western blotting assay confirmed the successful expression of rP35 (Figure 2B), while the two bands in the right lane may mean the recombinant protein breaks in two, which could not separate for the similar molecular weight of P35 and MBP tag.

\section{Specific Polyclonal Antibodies Against rP35}

SPF chickens aged 10 days were immunized with rP35 or MBP for the first time and were immunized again after 14 days. Serum was collected on days $0,7,14,21$, and 28 after the first vaccination and detected simultaneously. The kinetics of antibody production in chickens demonstrated a significant increase after immunization with the antigens rP35 and MBP compared to the pre-immune serum (day 0) (Figure 2C). These results suggested that recombinant protein $\mathrm{rP} 35$ had immunogenicity and could stimulate the production of specific antibodies in chickens.

\section{Antigenicity of Recombinant Proteins}

To clarify whether P35 has antigenicity, forward and reverse assays were carried out. On the one hand, we used SPF chicken polyantiserum of rP35 and MBP as primary antibodies to react with different MS strains in both ELISA and Western blotting assay. The results showed that significantly higher $\mathrm{P} / \mathrm{N}$ values 
A

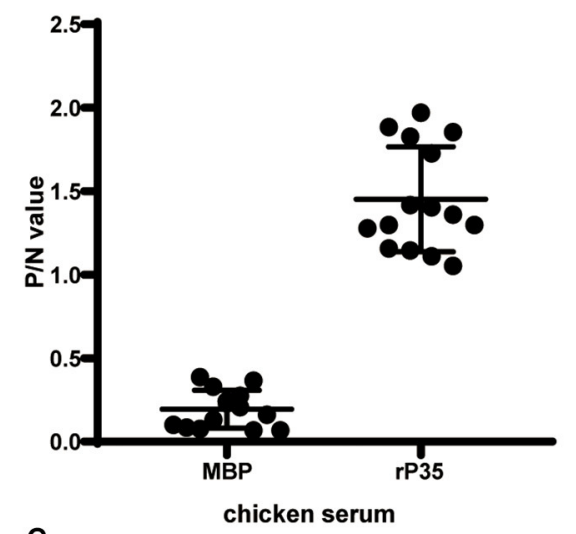

c

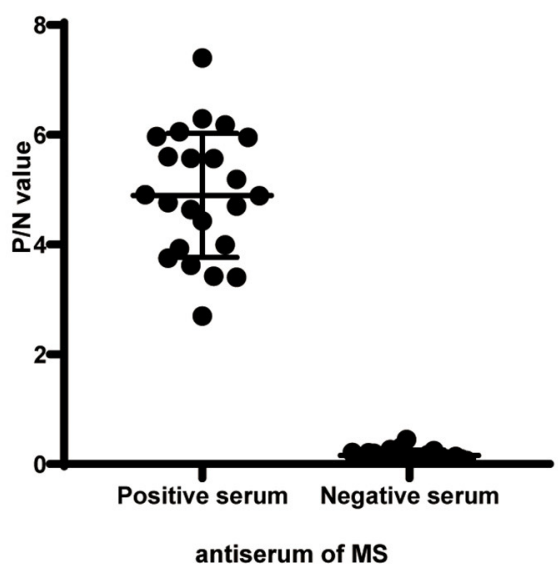

B
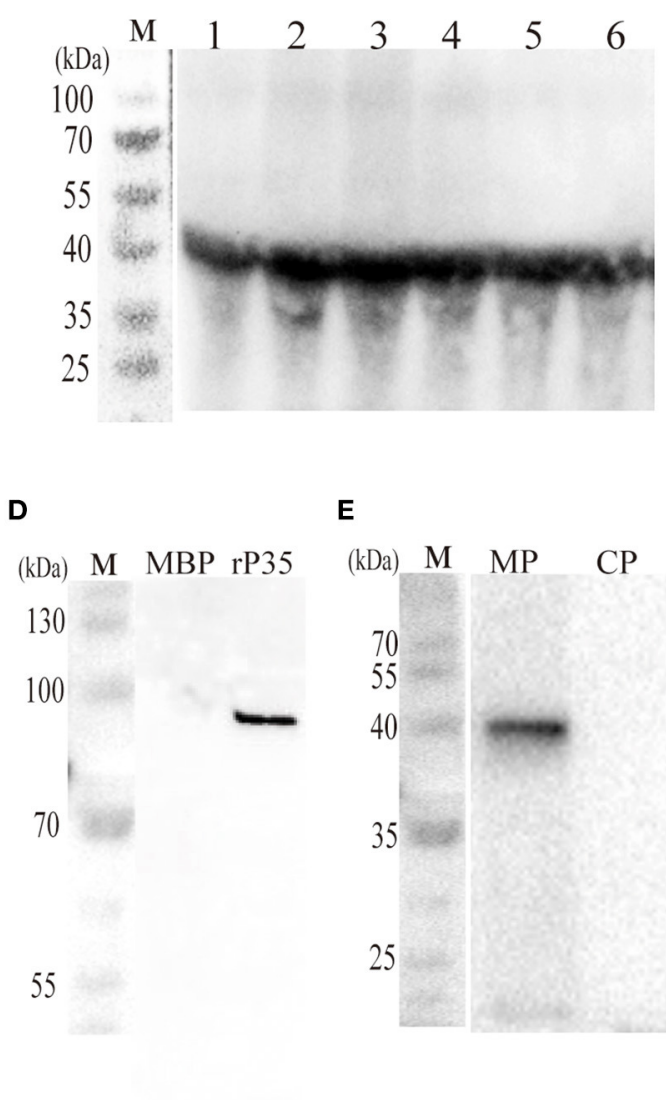

(kDa) $\mathrm{M} \quad \mathrm{MP} \quad \mathrm{CP}$

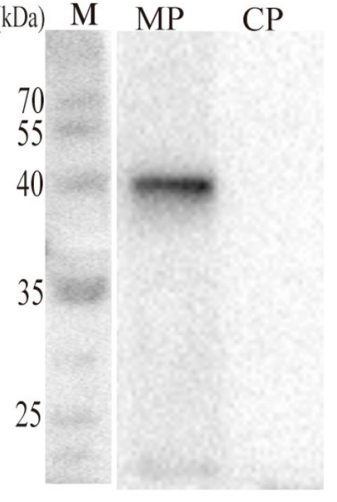

FIGURE 3 | Antigenicity analysis and localization of P35. (A) ELISA plates were coated with different Mycoplasma synoviae (MS) strains (10 ${ }^{8}$ CCU/well) and incubated with chicken serum against MBP and rP35 as the primary antibodies. (B) Western blotting assay of different MS strains incubated with chicken serum against rP35. (C) ELISAs were coated with rP35 and incubated with positive and negative specific pathogen-free (SPF) chicken serum against MS as the primary antibodies. (D) Western blotting assay of MBP and rP35 incubated with positive SPF chicken serum against MS. (E) Localization of P35. Western blotting assay was carried out after extracting the membrane protein of MS. MP means the membrane protein and CP means the cytoplasmic protein. The primary antibody used was SPF chicken serum against rP35.

occurred between antiserum of rP35 and MS strains, and the values of $\mathrm{P} / \mathrm{N}$ between antiserum of $\mathrm{MBP}$ and $\mathrm{MS}$ strains were of nearly basal level (Figure 3A). Correspondingly, a specific band can be observed obviously in Western blotting results (Figure 3B). On the other hand, we tested the reactivity of rP35 with antiserums of MS. In ELISA, positive and negative chicken serum samples of anti-MS were used to react with recombinant protein. The $\mathrm{P} / \mathrm{N}$ values of positive serum samples were significantly higher than those of negative serum samples (Figure 3C). The results of Western blotting showed that the recombinant protein was recognized by positive anti-MS chicken serum, and there was no band in the lane of MBP (Figure 3D). These results proved that $\mathrm{P} 35$ protein is antigenic.

\section{Cellular Localization of the P35}

Although bioinformatic analysis showed that P35 was an MS membrane protein, it was necessary to confirm this conclusion by molecular biology method. We extracted the membrane protein of MS with a commercial kit. The obtained membrane protein mixture and cytoplasmic protein mixture were subjected to Western blotting with rP35 antiserum as the primary antibody. The results showed that a specific band was observed in the membrane protein lane (Figure 3E). Besides, we visually observed whether P35 was located on the cell membrane by fluorescence microscope in a state where the cells were not being permeated. As expected, a strong green fluorescent signal was observed under the microscope (Figure 4). In short, these studies suggested that p35 was located on the cell membrane.

\section{Immune Epitope Region of P35}

In order to identify which regions of P35 have antigenicity, we truncated protein into five segments and expressed as SP1SP5 (Figure 5A). Purification of the SP1 segment failed (data 

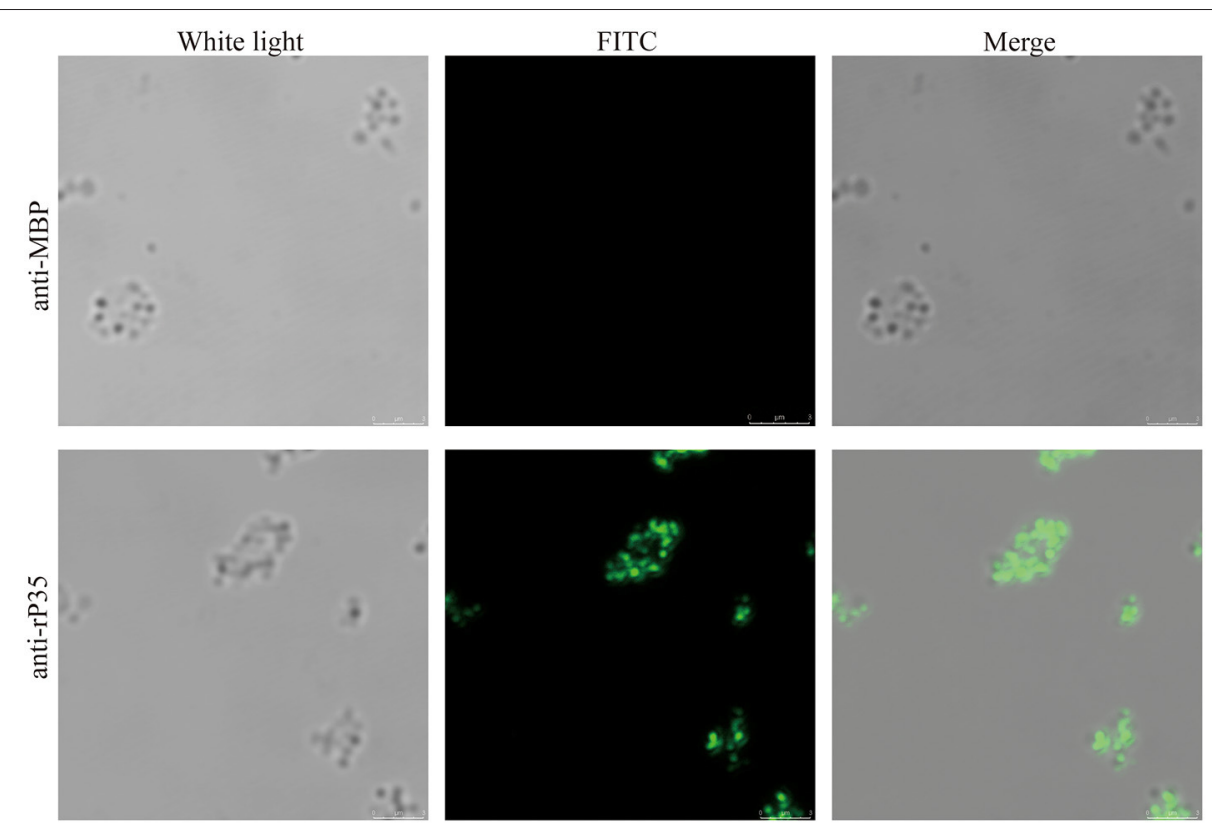

FIGURE 4 | Immunofluorescence assays of P35. After being washed twice, Mycoplasma synoviae (MS) cells were incubated with specific pathogen-free (SPF) chicken serum against rP35 and MBP without being permeated. Secondary antibody was fluorescein isothiocyanate (FITC)-conjugated goat anti-chicken lgG. Scale bars indicate $3 \mu \mathrm{m}$.

not shown). Thus, SP2-SP5 segments were used to test the antigenicity. In the ELISA, truncated segments were coated at the same concentration.

The results showed that the $\mathrm{P} / \mathrm{N}$ values of four truncated segments, reacting with chicken antiserum of MS, were higher than 0.681, while values of $\mathrm{MBP}$ reacted with antiserum were lower than 0.172 (Figure 5B). Western blotting assay also approved the specific reaction between four truncated segments and antiserum of MS, and no band was observed in the lane of MBP (Figure 5C). These results suggested that the P35 protein has several immune epitopes, which are dispersed in various regions of the protein.

\section{DISCUSSION}

MS is a major avian pathogen and is one of the main pathogens causing respiratory tract infection and joint swelling in chickens. MS is distributed worldwide and causes serious economic losses to the global poultry industry every year. Research on MS can lay the foundation for the prevention, diagnosis, and treatment of MS-related diseases (20). Previous studies have screened several immunogenic proteins from MS isolates (21). Bioinformatic analysis showed that there are still a large number of MS proteins that have not been identified, some of which are immunogenic proteins. In the present study, we identified a novel MS protein (P35) that has immunogenicity and antigenicity. To our knowledge, this was the first study to propose P35 in MS even in mycoplasma, which limits the speed of in-depth research on the structure, function, and so on due to the lack of relevant studies as a reference.

Firstly, we aligned the P35 protein with BLASTp and hoped to find some additional information about it. However, no known protein was aligned (Figure 1A). Then, we analyzed the sequence similarity of $p 35$ genes of different MS strains. It was found that $p 35$ genes were conservative, and the lowest sequence identify was $99.3 \%$ (Figure 1B). Therefore, we determined that P35 had value for further study.

For a novel conserved protein, one of our primary concerns is whether P35 is an antigen of MS. To verify it, we expressed rP35 and raised its polyantiserum. After immunization with rP35, chickens produced specific antibodies (Figure 2C), which suggested that rP35 has immunogenicity. Then we designed assays to identify the antigenicity of P35 (Figure 3). Firstly, we let the rP35 and MBP react with the chicken positive anti-MS serum samples in, respectively, ELISA and Western blotting assay. Significant reactivity was detected between rP35 and antiserums rather than MBP. Then, we used antiserum of $\mathrm{rP} 35$ and MBP to react with different MS isolated strains. As expected, a positive reaction occurred between MS strains and antiserum of rP35. At this point, we proved that P35 had immunogenicity and antigenicity and was an antigen of MS. However, whether immunization with P35 can protect chickens against MS infection needs further study.

The molecular weight of expressed recombinant protein indicated in Western blotting analysis is $87 \mathrm{kDa}$, which is consistent with the estimated molecular weight by 


\section{A}

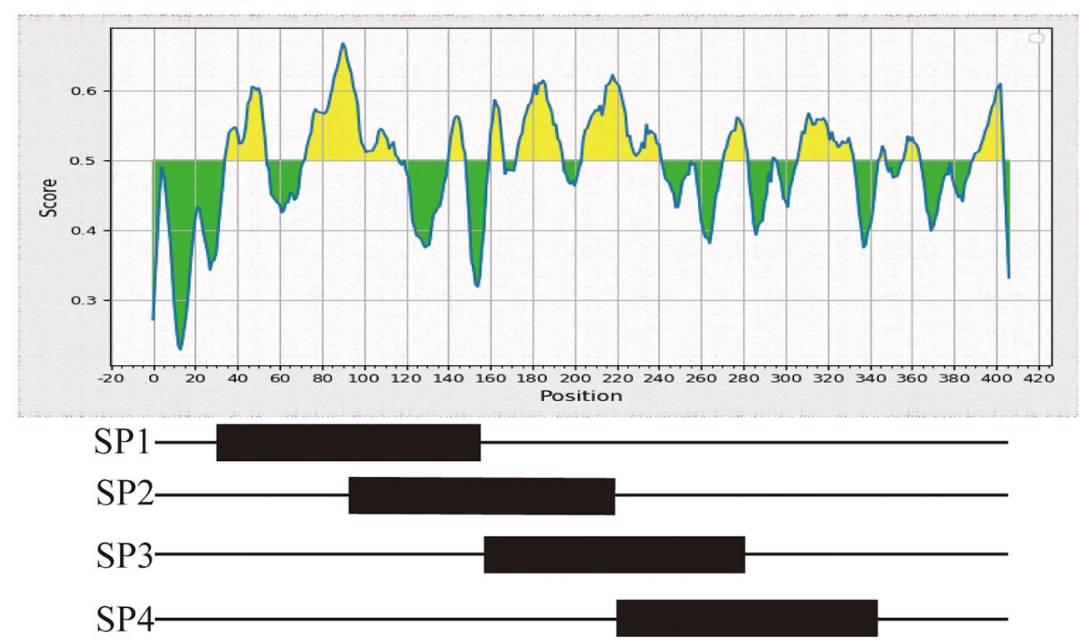

SP5-

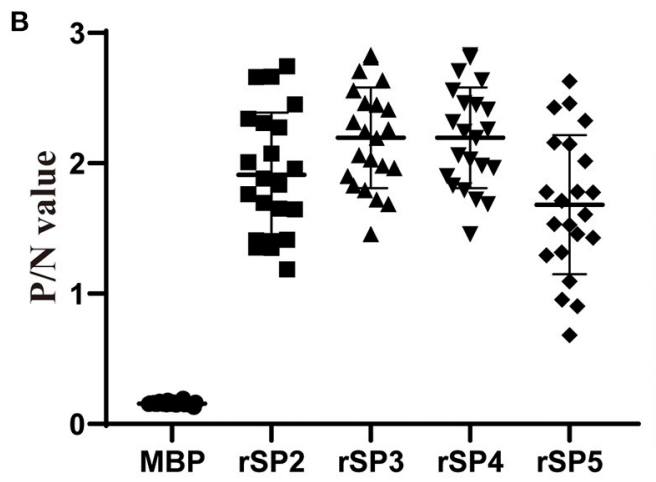

C

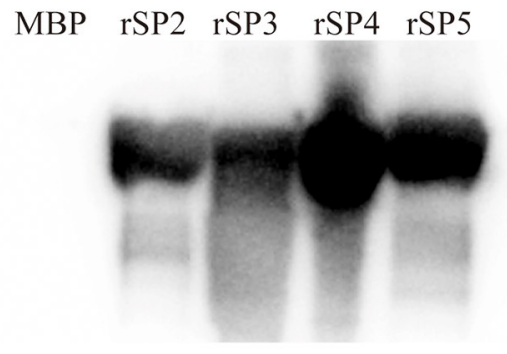

FIGURE 5 | Immune epitope analysis of P35. (A) Schematic diagram of truncated expression of P35. Excluding the signal peptide region, P35 protein was divided into five segments, and half the sequence repeats are between adjacent segments. (B) ELISAs were developed by coating plates with rSP2, rSP3, rSP4, and rSP5 segments and incubated with chicken serum against Mycoplasma synoviae (MS) as primary antibody, and MBP was coated as the negative control. (C) Western blotting assay of rSP2, rSP3, rSP4, and rSP5 segments reacted with chicken serum against MS. MBP was used as the negative control.

bioinformatic analysis; however, there have been other $40-\mathrm{kDa}$ protein bands. It is common especially for large proteins to have multiple bands due to protein truncation $(32,33)$. Truncated proteins are due to protein degradation or premature termination in ribosomes. Several studies on the expression of recombinant MBP fusion proteins faced this issue and considered it as a normal situation $(34,35)$.

In the present study, we also designed assays to express truncated segments to identify the immunogenic peptides of P35. However, four of the five truncated segments were successfully expressed, and all of the four segments could react with positive anti-MS serum samples. This result indicated that more than one immune peptide existed in P35.

In conclusion, in the present study, we identified a novel conserved membrane protein of MS. Furthermore, immunological studies confirmed that P35 protein had immunogenicity and antigenicity and was an MS antigen, which means that P35 may be a potential candidate against MS. However, other characteristics of P35 such as the molecular function, spatial structures, and immune protection need to be further studied.

\section{DATA AVAILABILITY STATEMENT}

The original contributions presented in the study are included in the article/supplementary material, further inquiries can be directed to the corresponding author/s.

\section{ETHICS STATEMENT}

The animal study was reviewed and approved by the Institutional Animal Care and Use Committee of Sun Yat-sen University (SYSU-IACUC-2021-B0507). 


\section{AUTHOR CONTRIBUTIONS}

XW and FC analyzed the genome of MS and designed this study. QS and WC prepared the recombinant protein. QZhong and $\mathrm{ZY}$ did the immunogenicity analysis of the protein. XW wrote the manuscript. QZhou, YC, and FC revised and corrected it. All authors contributed to the article and approved the submitted version.

\section{REFERENCES}

1. Sui C, Cui H, Ji J, Xu X, Kan Y, Yao L, et al. Epidemiological investigations and locally determined genotype diversity of Mycoplasma synoviae in Central China from 2017 to (2019). Poult Sci. (2022) 101:101522. doi: 10.1016/j.psj.2021.101522

2. Liu R, Xu B, Zhang J, Sun H, Liu C, Lu F, et al. Mycoplasma synoviae induces serum amyloid A upregulation and promotes chicken synovial fibroblast cell proliferation. Microb Pathog. (2021) 154:104829. doi: 10.1016/j.micpath.2021.104829

3. $\mathrm{Xu} \mathrm{B}$, Liu $\mathrm{R}$, Ding $\mathrm{M}$, Zhang J, Sun $\mathrm{H}$, Liu $\mathrm{C}$, et al. Interaction of Mycoplasma synoviae with chicken synovial sheath cells contributes to macrophage recruitment and inflammation. Poult Sci. (2020) 99:536677. doi: 10.1016/j.psj.2020.08.003

4. Dufour-Gesbert F, Dheilly A, Marois C, Kempf I. Epidemiological study on Mycoplasma synoviae infection in layers. Vet Microbiol. (2006) 114:14854. doi: 10.1016/j.vetmic.2005.10.040

5. Kursa O, Pakula A, Tomczyk G, Pasko S, Sawicka A. Eggshell apex abnormalities caused by two different Mycoplasma synoviae genotypes and evaluation of eggshell anomalies by full-field optical coherence tomography. BMC Vet Res. (2019) 15:1. doi: 10.1186/s12917-018-1758-8

6. Michiels T, Welby S, Vanrobaeys M, Quinet C, Rouffaer L, Lens L, et al. Prevalence of Mycoplasma gallisepticum and Mycoplasma synoviae in commercial poultry, racing pigeons and wild birds in Belgium. Avian Pathol. (2016) 45:244-52. doi: 10.1080/03079457.2016.1145354

7. Narasinakuppe Krishnegowda D, Singh BR, Mariappan AK, Munuswamy P, Singh KP, Monalisa S, et al. Molecular epidemiological studies on avian pathogenic Escherichia coli associated with septicemia in chickens in India. Microb Pathog. (2021) 162:105313. doi: 10.1016/j.micpath.2021.105313

8. Hutton S, Bettridge J, Christley R, Habte T, Ganapathy K. Detection of infectious bronchitis virus 793B, avian metapneumovirus, Mycoplasma gallisepticum and Mycoplasma synoviae in poultry in Ethiopia. Trop Anim Health Prod. (2017) 49:317-22. doi: 10.1007/s11250-016-1195-2

9. MacDonald AM, Jardine CM, Rejman E, Barta JR, Bowman J, Cai HY, et al. High prevalence of mycoplasma and eimeria species in free-ranging eastern wild turkeys (Meleagris Gallopavo Silvestris) in Ontario, Canada. J Wildl Dis. (2019) 55:54-63. doi: 10.7589/2017-11-273

10. Raviv Z, Ferguson-Noel N, Laibinis V, Wooten R, Kleven HS. Role of Mycoplasma synoviae in commercial layer Escherichia coli peritonitis syndrome. Avian Dis. (2007) 51:685-90. doi: 10.1637/00052086(2007)51[685:ROMSIC]2.0.CO;2

11. Zhang X, Guo M, Xie D, Chen Y, Zhang C, Cao Y, et al. Antibiotic resistance of Mycoplasma synoviae strains isolated in China from 2016 to 2019. BMC Vet Res. (2022) 18:1. doi: 10.1186/s12917-021-03104-4

12. Abd El-Hamid MI, Awad NFS, Hashem YM, Abdel-Rahman MA, Abdelaziz AM, Mohammed IAA, et al. In vitro evaluation of various antimicrobials against field mycoplasma gallisepticum and Mycoplasma synoviae isolates in Egypt. Poult Sci. (2019) 98:6281-8. doi: 10.3382/ps/pez576

13. Gautier-Bouchardon AV. Antimicrobial resistance in Mycoplasma spp. Microbiol Spectr. (2018) 6. doi: 10.1128/microbiolspec.ARBA-0030-2018

14. Gong X, Chen Q, Ferguson-Noel N, Stipkovits L, Szathmary S, Liu Y, et al. Evaluation of protective efficacy of inactivated Mycoplasma synoviae vaccine with different adjuvants. Vet Immunol Immunopathol. (2020) 220:109995. doi: 10.1016/j.vetimm.2019.109995

15. Zhu L, Shahid MA, Markham J, Browning GF, Noormohammadi AH, Marenda SM. Comparative genomic analyses of Mycoplasma synoviae vaccine

\section{FUNDING}

$\begin{array}{lllr}\text { This work was supported by the } & \text { Guangdong } \\ \text { Basic and Applied Basic } & \text { Research } & \text { Foundation } \\ \text { (2019A1515012006), } & \text { Key } & \text { Research } & \text { and } \\ \text { Development Program of } & \text { Guangdong } & \text { Province } \\ \text { (2020B020222001), and China } & \text { Postdoctoral } & \text { Science }\end{array}$

Foundation (2021M692455).

strain MS-H and its wild-type parent strain 86079/7NS: implications for the identification of virulence factors and applications in diagnosis of M. synoviae. Avian Pathol. (2019) 48:537-48. doi: 10.1080/03079457.2019.1637514

16. Cortes V, Sevilla-Navarro S, Garcia C, Tudon A, Marin C, CatalaGregori P. Seroprevalence and prevalence of Mycoplasma synoviae in laying hens and broiler breeders in Spain. Poult Sci. (2021) 100:100911. doi: 10.1016/j.psj.2020.11.076

17. Sun SK, Lin X, Chen F, Wang DA, Lu JP, Qin JP, et al. Epidemiological investigation of Mycoplasma synoviae in native chicken breeds in China. BMC Vet Res. (2017) 13:115. doi: 10.1186/s12917-017-1029-0

18. Maniloff J. Mycoplasma viruses. Crit Rev Microbiol. (1988) 15:33989. doi: 10.3109/10408418809104462

19. Razin S, Hayflick L. Highlights of mycoplasma researchan historical perspective. Biologicals. (2010) 38:18390. doi: 10.1016/j.biologicals.2009.11.008

20. Bao S, Ding X, Yu S, Xing X, Ding C. Characterization of pyruvate dehydrogenase complex E1 alpha and beta subunits of Mycoplasma synoviae. Microb Pathog. (2021) 155:104851. doi: 10.1016/j.micpath.2021.104851

21. Bercic RL, Slavec B, Lavric M, Narat M, Bidovec A, Dovc P, et al. Identification of major immunogenic proteins of Mycoplasma synoviae isolates. Vet Microbiol. (2008) 127:147-54. doi: 10.1016/j.vetmic.2007.07.020

22. Chen $\mathrm{X}$, Huang J, Zhu $\mathrm{H}$, Guo $\mathrm{Y}$, Khan FA, Menghwar $\mathrm{H}$, et al. P27 (MBOV_RS03440) is a novel fibronectin binding adhesin of Mycoplasma bovis. Int J Med Microbiol. (2018) 308:848-57. doi: 10.1016/j.ijmm.2018.07.006

23. Adamu JY, Wawegama NK, Kanci Condello A, Marenda MS, Markham PF, Browning GF, et al. Mycoplasma bovis membrane protein MilA is a multifunctional lipase with novel lipid and glycosaminoglycan binding activity. Infect Immun. (2020) 88:e00945-19. doi: 10.1128/IAI.00945-19

24. Sirand-Pugnet P, Lartigue C, Marenda M, Jacob D, Barre A, Barbe V, et al. Being pathogenic, plastic, and sexual while living with a nearly minimal bacterial genome. PLoS Genet. (2007) 3:e75. doi: 10.1371/journal.pgen.0030075

25. Mitiku F, Hartley CA, Sansom FM, Coombe JE, Mansell PD, Beggs DS, et al. The major membrane nuclease MnuA degrades neutrophil extracellular traps induced by Mycoplasma bovis. Vet Microbiol. (2018) 218:13-9. doi: 10.1016/j.vetmic.2018.03.002

26. Szczepanek SM, Frasca S Jr, Schumacher VL, Liao X, Padula M, Djordjevic SP, et al. Identification of lipoprotein MslA as a neoteric virulence factor of Mycoplasma gallisepticum. Infect Immun. (2010) 78:347583. doi: 10.1128/IAI.00154-10

27. Calcutt MJ, Lysnyansky I, Sachse K, Fox LK, Nicholas RAJ, Ayling DR. Gap analysis of Mycoplasma bovis disease, diagnosis and control: an aid to identify future development requirements. Transbound Emerg Dis. (2018) 65(Suppl. 1):91-109. doi: 10.1111/tbed.12860

28. Yu NY, Wagner JR, Laird MR, Melli G, Rey S, Lo R, et al. PSORTb 3.0: improved protein subcellular localization prediction with refined localization subcategories and predictive capabilities for all prokaryotes. Bioinformatics. (2010) 26:1608-15. doi: 10.1093/bioinformatics/btq249

29. Berven FS, Flikka K, Jensen HB, Eidhammer I. BOMP: a program to predict integral beta-barrel outer membrane proteins encoded within genomes of Gram-negative bacteria. Nucleic Acids Res. (2004) 32(Web Server issue):W394-W9. doi: 10.1093/nar/gkh351

30. El-Gebali S, Mistry J, Bateman A, Eddy SR, Luciani A, Potter SC, et al. The Pfam protein families database in 2019. Nucleic Acids Res. (2019) 47:D427D32. doi: 10.1093/nar/gky995 
31. Bogema DR, Scott NE, Padula MP, Tacchi JL, Raymond BBA, Jenkins C, et al. Sequence TTKF downward arrow QE defines the site of proteolytic cleavage in Mhp683 protein, a novel glycosaminoglycan and cilium adhesin of Mycoplasma hyopneumoniae. J Biol Chem. (2011) 286:4121729. doi: 10.1074/jbc.M111.226084

32. Whitaker WR, Lee H, Arkin AP, Dueber EJ. Avoidance of truncated proteins from unintended ribosome binding sites within heterologous protein coding sequences. ACS Synth Biol. (2015) 4:249-57. doi: 10.1021/sb500003x

33. Akbarzadeh-Niaki M, Derakhshandeh A, Kazemipour N, Eraghi V, Hemmatzadeh F. A novel chimeric recombinant protein PDHB-P80 of Mycoplasma agalactiae as a potential diagnostic tool. Mol Biol Res Commun. (2020) 9:123-8. doi: 10.22099/mbrc.2020.37684.1513

34. Hemmatzadeh F, Sumarningsih S, Tarigan S, Indriani R, Dharmayanti NL, Ebrahimie E, et al. Recombinant M2e protein-based ELISA: a novel and inexpensive approach for differentiating avian influenza infected chickens from vaccinated ones. PLoS One. (2013) 8:e56801. doi: 10.1371/journal.pone.0056801

35. Salema V, Fernandez LA. High yield purification of nanobodies from the periplasm of $E$. coli as fusions with the maltose binding protein. Protein Expr Purif. (2013) 91:42-8. doi: 10.1016/j.pep.2013. 07.001
Conflict of Interest: XW and YC were employed by Wen's Foodstuffs Group Co., Ltd.

The remaining authors declare that the research was conducted in the absence of any commercial or financial relationships that could be construed as a potential conflict of interest.

Publisher's Note: All claims expressed in this article are solely those of the authors and do not necessarily represent those of their affiliated organizations, or those of the publisher, the editors and the reviewers. Any product that may be evaluated in this article, or claim that may be made by its manufacturer, is not guaranteed or endorsed by the publisher.

Copyright (c) 2022 Sun, Wei, Chen, Zhong, Yan, Zhou, Cao and Chen. This is an open-access article distributed under the terms of the Creative Commons Attribution License (CC BY). The use, distribution or reproduction in other forums is permitted, provided the original author(s) and the copyright owner(s) are credited and that the original publication in this journal is cited, in accordance with accepted academic practice. No use, distribution or reproduction is permitted which does not comply with these terms. 